\title{
Improved Wear Resistance of Boron Steels by Subcritical Annealing and Hardening with Production Cost Savings and Lower Environmental Impact
}

Queirós GW, García Sánchez L*, Gómez de Salazar JM and Criado Portal AJ

Department of Materials Science and Metallurgical Engineering, School of Chemistry, Complutense University of Madrid, 28040 Madrid, Spain

\begin{abstract}
Boron steels are very interesting as wear resistant materials. In this research we propose a boron steel without alloys, 30MnB5, with a new thermal treatment that exceeds the mechanical characteristics of conventional treatment. The 30MnB5 steel, with the new sub-critical annealing and water quenching heat treatment, also exceeds the RAEX450. The new treatment has important advantages, such as: energy savings and reduction of costs and manufacturing times. It also has a more favourable ACV than 30MnB5 with conventional heat treatment and RAEX450. Its wear resistance is significantly improved compared to the classic heat-treated 30MnB5 and the RAEX450.
\end{abstract}

Keywords: Boron steel; Heat treatment; Metallographic structures; Mechanical properties

\section{Introduction}

The hardness obtained after hardening of these steels in water makes them particularly suitable for applications where high resistance to wear is required.

The use of these steels allows reductions in the weight of very considerable structures, up to $40 \%$ in weight compared to several types of steels, among others, compared to HSLA (High Strength Low Alloy). Its fatigue resistance is also much higher than HSLA, from $40 \%$ to $60 \%$.

They have an excellent performance for hardening in water, which results in environmental impact, compared to other carbon steels [1-10].

The applications of boron steels, after the thermal treatment of hardening in water, are directed to agricultural or public works machinery, mining, cutting equipment, etc., as a suitable material because of its resistance to wear.

Two types of boron steels have been used in this study: one carbon steels, 30MnB5 (UNE-EN 10083-3:2006) and one slightly alloyed RAEX450. RAEX450 steel, we have used it as a reference material, because our aim is to propose $30 \mathrm{MnB} 5$ steel, without alloy, as a prototype for its best LCA (Life Cycle Analysis) [11,12], since it lacks alloying elements, such as chromium, nickel and molybdenum. It also affects the price.

A new water quenching heat treatment has been designed for these steels, which represents an innovation. It is a matter of achieving hardening from a low temperature, such as $750^{\circ} \mathrm{C}$, and with a very short cycle heating, from 10 to 15 minutes. It is a subcritical hardening from the binary field of existence ferrite+austenite. The structure obtained is binary, formed by ferrite and martensite [12]. The relative percentages of these phases provide a great variability in the mechanical properties; depending, only, on the variables temperature and time. This makes the annealing stage unnecessary. It is an important success because it reduces annealing times and a stage in the hardening and tempering process, reduces production costs and has a very favourable environmental impact [12]. It is even possible to improve some of its mechanical properties. All this was evident in the work published by García and Criado [12], in which the mechanical properties obtained for this thermal treatment of subcritical annealing and hardening of boron steels were compared with 30MnB5. The mechanical properties were of a similar order to those obtained by conventional hardening and tempering treatment, but with certain improvements in toughness and hardness. In this research, steel $30 \mathrm{MnB} 5$, is treated by means of the new sub-critical annealing and hardening heat treatment and we have tried to see its wear behaviour, which is the industrial use of these boron steels. To see its improvement in terms of wear resistance, we have chosen RAEX450 steel as a reference, whose application as wearresistant steel is widely used.

\section{Experimental Technique}

Two types of boro-manganese steels have been selected for this research: 30MnB5 (UNE-EN 10083-3:2006) and RAEX450 001-01-01 (SSAB?s Certified Partner). The $30 \mathrm{MnB} 5$ is a carbon steel of high wear resistance in its quenching state and the RAEX450 is an alloyed boronmanganese steel with similar mechanical performance. The chemical composition of both steels is shown in Table 1 .

\begin{tabular}{|c|c|c|}
\hline & 30MnB5 & RAEX 450 \\
\hline C & 0.3 & 0.26 \\
\hline Mn & 1.3 & 1.7 \\
\hline $\mathrm{P}$ & $<0.035$ & 0.025 \\
\hline $\mathrm{S}$ & $<0.035$ & 0.015 \\
\hline $\mathrm{Si}$ & 0.3 & 0.8 \\
\hline $\mathrm{Si}$ & 0.95 & 1.5 \\
\hline $\mathrm{B}$ & - & 1 \\
\hline $\mathrm{Mo}$ & 0.003 & 0.005 \\
\hline
\end{tabular}

Table 1: Compositions of steels (\% by mass content): $30 \mathrm{MnB} 5$ and RAEX 450.

*Corresponding author: Laura García Sánchez, Department of Materials Science and Metallurgical Engineering, School of Chemistry, Complutense University of Madrid, 28040 Madrid, Spain, Tel: (+34) 91.394.42.86; Fax: (+34) 91.394.43.57; E-mail: gslaura@quim.ucm.es

Received December 12, 2017; Accepted December 19, 2017; Published January 03, 2018

Citation: Queirós GW, Sánchez LG, Salazar JMGD, Portal AJC (2018) Improved Wear Resistance of Boron Steels by Subcritical Annealing and Hardening with Production Cost Savings and Lower Environmental Impact. J Material Sci Eng 7: 411. doi: 10.4172/2169-0022.1000411

Copyright: (c) 2018 Queirós GW, et al. This is an open-access article distributed under the terms of the Creative Commons Attribution License, which permits unrestricted use, distribution, and reproduction in any medium, provided the original author and source are credited. 
Citation: Queirós GW, Sánchez LG, Salazar JMGD, Portal AJC (2018) Improved Wear Resistance of Boron Steels by Subcritical Annealing and Hardening with Production Cost Savings and Lower Environmental Impact. J Material Sci Eng 7: 411. doi: 10.4172/2169-0022.1000411

Page 2 of 4

They were acquired in the form of wire rod drawn wire, steel $30 \mathrm{MnB} 5$, up to diameters of $7.02 \mathrm{~mm}, 8.84 \mathrm{~mm}$ and $12.79 \mathrm{~mm}$ (Figure 1). RAEX450 steel was acquired in the form of an $8 \mathrm{~mm}$ thick plate (Figure 2), with heat treatment of hardening and tempering, ready to be used in the typical industrial applications of these steels: hardened from $900^{\circ} \mathrm{C}$ and tempered at $500^{\circ} \mathrm{C}$.

From these starting materials were obtained samples that were heat treated in a Carbolite muffle, model ELF-11/148 series S336RB, with thermal capacity of $1100^{\circ} \mathrm{C}$.

For micro-hardness measurements, a Vickers FUTURE-TECH micro-hardness tester was used, model FM-700, with a variable load from $10 \mathrm{~kg}$ to $100 \mathrm{~kg}$.

The Rockwell-C hardness determination has been carried out on a universal hardness tester OFFICINE GALILEO, model A200, with a $150 \mathrm{~kg}$ load, using the Brale diamond cone tip penetrator.

For tribological tests, the specimens were roughed to a sandpaper of 600 grams per square inch, then subjected to the wear test on a CENT UMT Multi-Specium Test System Pin-On-Disk tribometer, taking as a reference the ASTM International G99-95a(2000)el standard with a tungsten carbide pin [13].

Figures 3 and 4 show the type of samples tested, extracted from the reception materials (Figures 1 and 2), used for heat treatments and hardness, micro-hardness, tribology and metallography tests.

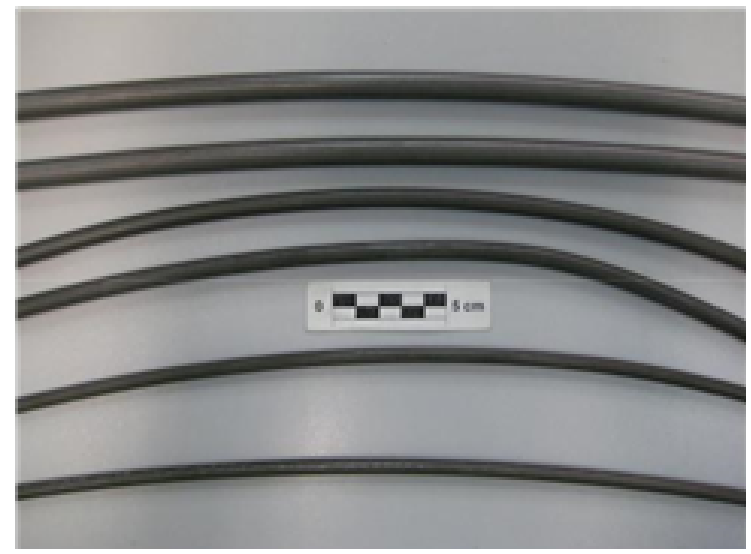

Figure 1: Wire rods of boron steel (30MnB5) drawn wire.

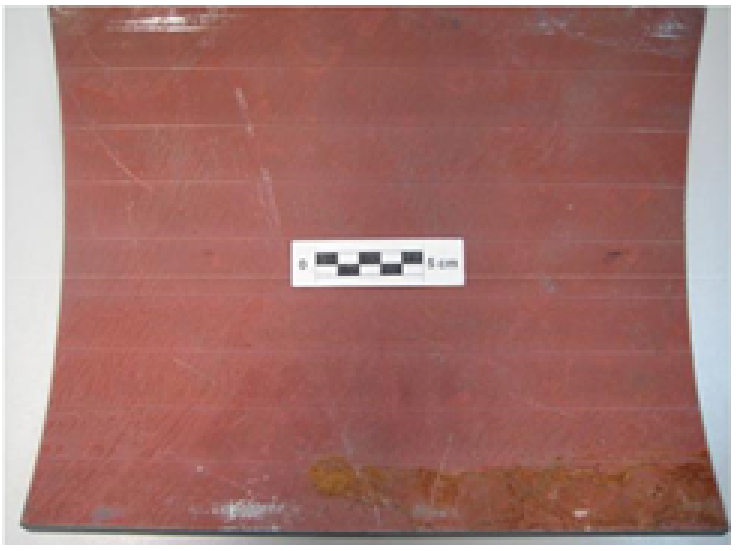

Figure 2: Alloyed boron steel sheet RAEX 450.

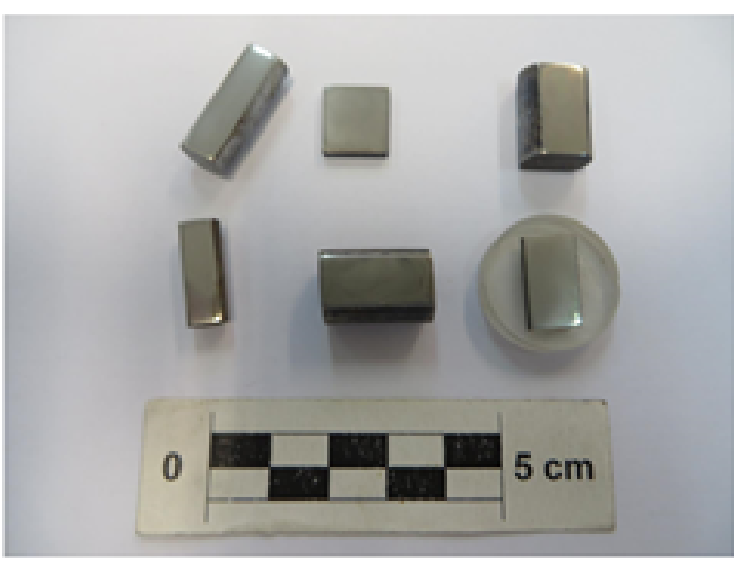

Figure 3: Used specimens of boron steel 30MnB5.

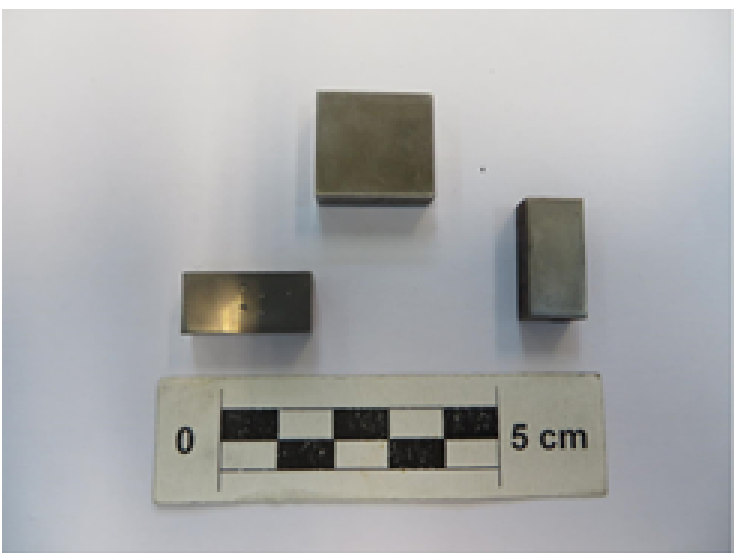

Figure 4: Used specimens of boron steel RAEX450.

\section{Results and Discussion}

RAEX450 steel was received with heat treatments already carried out directly by the trading company. They come with the mechanical properties derived from the conventional industrial thermal treatment applied to this type of steel, quenching in water from $900^{\circ} \mathrm{C}$ and tempering at $500^{\circ} \mathrm{C}$. In that state the hardness found is $43 \mathrm{HRC}$.

The non-alloy boron steel, steel $30 \mathrm{MnB} 5$, was subjected to subcritical annealing heat treatments at $770^{\circ} \mathrm{C}$, variable time and hardening in water (Table 2). Without further heat treatments, they were tested. This demonstrates significant energy savings and process times.

The microstructure of the steels studied is the result of the heat treatment undergone. The RAEX450, which is already heat-treated, has a tempered martensitic structure (Figure 5). The unalloyed boron steel, $30 \mathrm{MnB} 5$, in its receiving state, presents a microstructure of iron carbides in scolonies distributed in a ferritic matrix of elongated grains, produced by the drawing process (Figure 6). This steel, treated by subcritical annealing at $770^{\circ} \mathrm{C}$ for 15 minutes and tempered in water, has a dual-phase microstructure with alternating martensite crystals of ferrite crystals (Figure 7). 
Citation: Queirós GW, Sánchez LG, Salazar JMGD, Portal AJC (2018) Improved Wear Resistance of Boron Steels by Subcritical Annealing and Hardening with Production Cost Savings and Lower Environmental Impact. J Material Sci Eng 7: 411. doi: 10.4172/2169-0022.1000411

Page 3 of 4

\begin{tabular}{|c|c|c|}
\hline Temperature $\left({ }^{\circ} \mathrm{C}\right)$ & Times (minutes) & Hardness (HRC) \\
\hline 770 & 10 & 51 \\
\hline 770 & 15 & 57 \\
\hline 770 & 20 & 54 \\
\hline 770 & 25 & 54 \\
\hline 770 & 30 & 52 \\
\hline
\end{tabular}

Table 2: Hardness of steel 30MnB5, depending on subcritical annealing time.

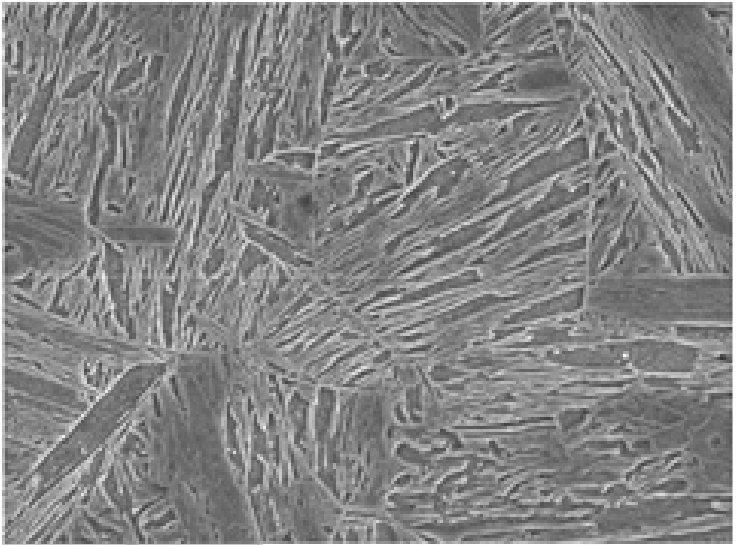

Figure 5: Microstructure of RAEX450 steel tempered from $900^{\circ} \mathrm{C}$ and tempered to $500^{\circ} \mathrm{C}$. A structure of tempered martensite is observed.

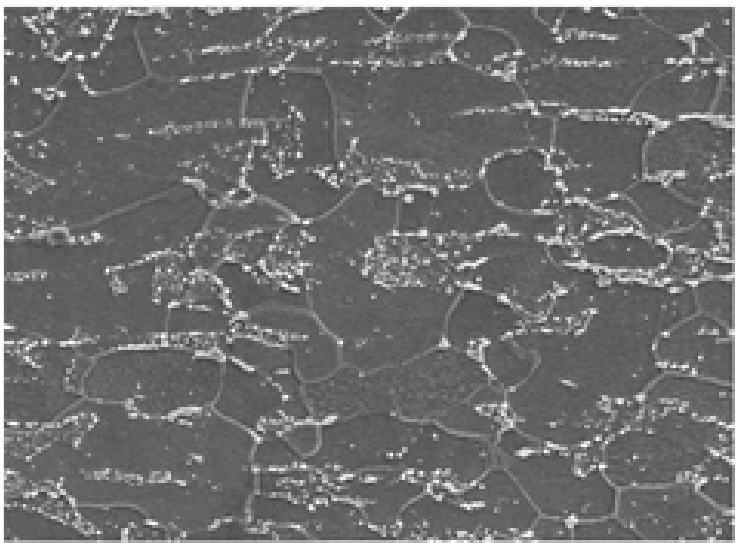

Figure 6: Microstructure of steel $30 \mathrm{MnB5}$ in receiving state. Iron carbide colonies are observed in a ferritic matrix, which corresponds to a hot-drawn structure.

The hardnesses obtained with these steels are suitable for industrial use, such as wear resistant steels. The factory heat-treated RAEX450 has a Rockwell hardness of 43HRC, while the non-alloy steel 30MnB5, with the different subcritical annealing times at $770^{\circ} \mathrm{C}$ and hardened in water, has hardnesses reflected in Table 2.

The steel $30 \mathrm{MnB} 5$ selected for other tests is subcritical annealing at $770^{\circ} \mathrm{C}$, for 15 minutes and hardened in water, which has a hardness of $57 \mathrm{HRC}$

In this research, we have considered the wear behaviour of both RAEX450 and 30MnB5 to be very important, with our subcritical annealing treatment, as this is the main application of these wearresistant steels. The aim is to see if, with the subcritical annealing treatment of $770^{\circ} \mathrm{C}$, during 15 minutes and quenching in water, an improvement in the coefficient of friction of steel $30 \mathrm{MnB} 5$ compared to the reference material, RAEX450, is observed. Tribological testing has been done under ASTM International standard G99-95a (2000)e1, with a tungsten carbide pin. The results obtained, after statistical study, give values for the coefficient of friction of $30 \mathrm{MnB} 5$ of 0.54 and, for the RAEX450 of 0.63 .

The justification for these values, which stand out as the best coefficient of friction for steel $30 \mathrm{MnB} 5$, is not that it is associated with higher hardness (57HRC), since the excellent toughness of $30 \mathrm{MnB} 5$ is demonstrated [12] with subcritical annealing and tempering treatment. This acceptable toughness for such high hardness is due to the dual phase ferrite-martensite microstructure.

The traces left by the tungsten carbide pin are of a different nature (Figures 8 and 9). In Figure 8, the wear pattern left by the tungsten carbide pin on $30 \mathrm{MnB} 5$ steel with subcritical annealing and water quenching is abrasive; whereas in Figure 9, the wear pattern left by the tungsten carbide pin on RAEX450 steel is clearly adhesive.

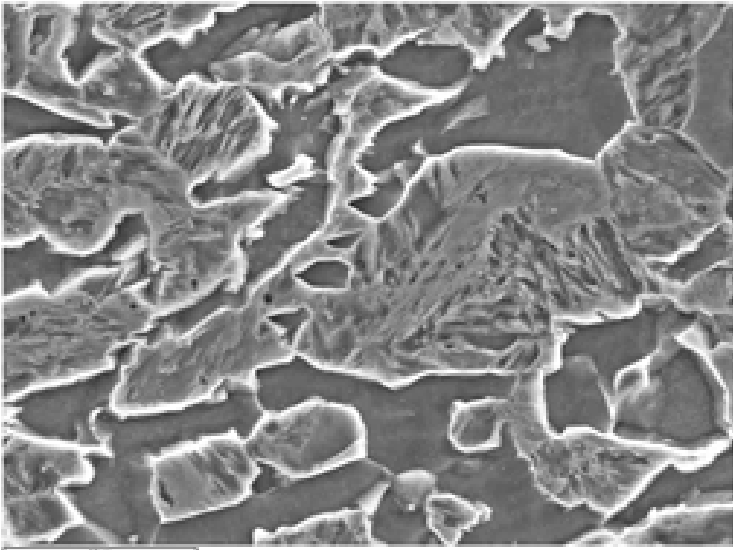

Figure 7: Microstructure of steel $30 \mathrm{MnB5}$ after subcritical annealing at $770^{\circ} \mathrm{C}$ for 15 minutes and tempered in water. A dual structure of martensite and ferrite is observed.

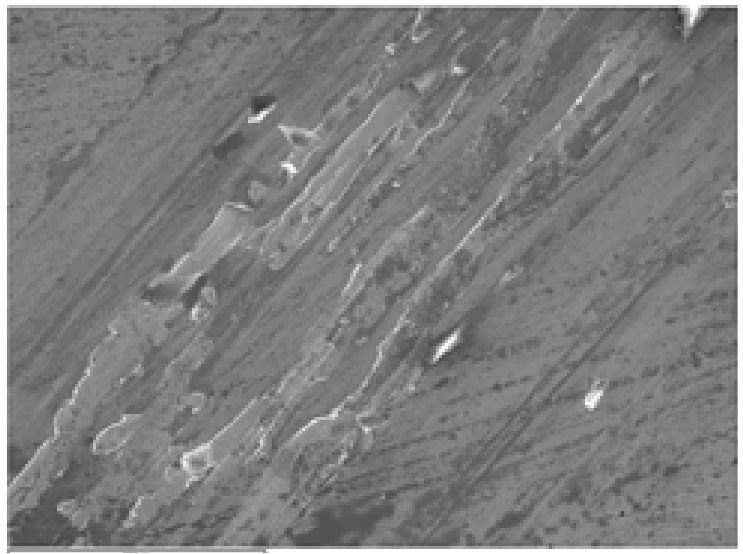

Figure 8: Wear pattern of steel $30 \mathrm{MnB} 5$ (recognized $770^{\circ} \mathrm{C}, 15 \mathrm{~min}$; hardened in water). The print has abrasive wear morphologies. 
Citation: Queirós GW, Sánchez LG, Salazar JMGD, Portal AJC (2018) Improved Wear Resistance of Boron Steels by Subcritical Annealing and Hardening with Production Cost Savings and Lower Environmental Impact. J Material Sci Eng 7: 411. doi: 10.4172/2169-0022.1000411

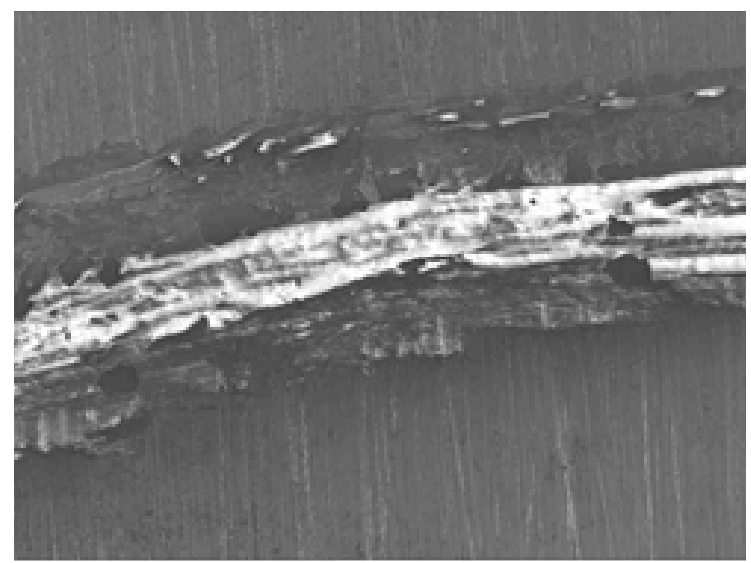

Figure 9: Wear pattern of RAEX450 steel (Recognized $900^{\circ} \mathrm{C}$; hardened in water; tempered $500^{\circ} \mathrm{C}$ ). The print has adhesive wear morphologies.

\section{Conclusions}

Boron steel 30MnB5, due to its chemical composition, presents a more favourable LCA (Life Cycle Analysis) than RAEX450 steels.

The heat treatment of steel $30 \mathrm{MnB} 5$ requires less time and a lower annealing temperature $\left(770^{\circ} \mathrm{C}\right)$ than RAEX450 $\left(900^{\circ} \mathrm{C}\right)$ and $30 \mathrm{MnB} 5$ itself by the current conventional method. The proposed new subcritical annealing and water quenching treatment does not require the RAEX450 tempering stage at $500^{\circ} \mathrm{C}$ for an extended period of time. Also, steel $30 \mathrm{MnB} 5$, according to the conventional treatment, needs this tempering stage after quenching in water, which our proposed treatment does not require.

Substantial energy savings occur during subcritical annealing, at a lower temperature and at the same time as those used conventionally for RAEX450 or $30 \mathrm{MnB} 5$ itself. The saving of the tempering stage means a very considerable advantage of the proposed new subcritical annealing treatment compared to the conventional treatment being used.

This very considerable energy saving results in a very favourable LCA for the proposed treatment of subcritical annealing.

The mechanical properties that are obtained with the new treatment, are of the same order or improved, to which they are obtained with the conventional thermal treatment of annealing, hardening and tempering. The cause that justifies this behaviour is the obtaining of a dual phase structure, consisting of a ferrite matrix with martensite crystals.

In this research we have found a greater hardness (57HRC) of $30 \mathrm{MnB5}$, with the proposed new treatment, compared to RAEX450 with conventional treatment (43HRC). This translates into a lower coefficient of friction of 0.54 for $30 \mathrm{MnB} 5$ steel compared to 0.63 for RAEX450 steel. Therefore, the wear behaviour is improved and, in addition, without loss of toughness by the $30 \mathrm{MnB} 5$.

Considering that the wear-resistant applications of these steels, an industry using plates and other medium thickness products is applied, $30 \mathrm{MnB} 5$ steel, treated with the proposed new heat treatment, is a strong competitor for RAEX steels, in all fields.

\section{References}

1. American Society for Metals (1953) Boron steel (2ndedn), American Society for Metals, Metals Park, New York.

2. Kapadia BM (1977) Prediction of the Boron Hardenability Effect in Steel-A Comprehensive Review. Hardenability Concepts with Applications to Steel, pp: 448-482.

3. Siebert C (1977) Hardenability of Steels-Concepts, Metallurgical Influences and Industrial Applications. ASM, Metals Park, Ohio, p: 218.

4. Gusejnov RK (1991) Properties of boron microalloyed structural steel. Metallovedenie i Termicheskaya Obrabotka Mettallov 7: 35-37.

5. Maitrepierre P, Thivellier D, Vernis JR (1977) Microstructure and hardenability of low alloy boron containing steels, hardenability concepts with applications to steel. In Conference Proceeding, Chicago, pp: 24-26.

6. Ghali SN, El-Faramawy HS, Eissa MM (2012) Influence of boron additions on mechanical properties of carbon steel. Journal of Minerals and Materials Characterization and Engineering 11: 995.

7. Huang Z, Xing J, Guo C (2010) Improving fracture toughness and hardness of Fe 2 B in high boron white cast iron by chromium addition. Materials \& Design 31: 3084-3089.

8. Kapadia BM (1987) Effect of boron addicions on toughness of heat-treated low alloy steel", Journal of Heat Treatment 5: 41-53.

9. Titova TI, Shulgan NA, Malykhina IY (2007) Effect of boron microalloying on the structure and hardenability of building steel. Metal science and heat treatment 49: 39-44.

10. Mejía I, Bedolla-Jacuinde A, Maldonado C, Cabrera JM (2011) Hot ductility behavior of a low carbon advanced high strength steel (AHSS) microalloyed with boron. Materials Science and Engineering: A 528: 4468-4474.

11. ISO 14001:20015 Enviromental management systems.Requirements with guidance for use.

12. Garcia SL, Criado Portal AJ (2015) Steel of Boron with Dual Structure fo Automobile Screws, Reducing Manufacturing Costs and Environmental Impact. J Material Sci Eng 4: 190

13. ASTM Designation: G99-95a (Reaproved 2000) e1. Standart Test Method for Wear Testing with a Pin-on-Disk Apparatus. May2000. 